\title{
Özel Tasarım Bir Gübre Sıyırıcı Küreğinin Yapısal ve İșlevsel Elemanlarında Sonlu Elemanlar Yöntemi ile Gerilme Analizi
}

\author{
İsmail Boyar ${ }^{1 *}$ \\ H. Kürşat Çelik ${ }^{2}$ \\ Deniz Yılmaz ${ }^{3}$
}

${ }^{1,2}$ Akdeniz Üniversitesi, Ziraat Fakültesi, Tarım Makinaları ve Teknolojileri Müh. Bölümü, Antalya, Türkiye.
${ }^{3}$ Isparta Uygulamalı Bilimler Üniversitesi, Ziraat Fakültesi, Tarım Makinaları ve Teknolojileri Müh. Bölümü, Isparta
${ }^{*}$ Sorumlu yazar: ismailboyar@ akdeniz.edu.tr
${ }^{1}$ https://orcid.org/0000-0001-6703-6022, ${ }^{2}$ https://orcid.org/0000-0001-8154-6993, ${ }^{3}$ https://orcid.org/0000-0003-3326-8890

Geliş Tarihi: 26.12.2019

Kabul Tarihi: 06.05.2020

Öz

Gübre sıyırıcılar genellikle 50 baş ve üzeri, büyükbaş hayvan yetiştiriciliğinin yapıldığı hayvancılık işletmelerinde kullanılan, insan iş yükünü azaltan basit yapılı ve işlevi yüksek tarım makinelerindendir. Bir bağ çekme düzeneği ile çalışan bu aletler çekilme yöntemine göre hidrolik (pistonlu) ve mekanik (zincirli) tip olmak üzere ikiye ayrılmaktadır. Özellikle zincirli tip sıyıcılar yaygın olarak kullanılmaktadır ancak bu tip makine ve alet tasarımlarında, ihtiyaç duyulan gereklilikleri karşılayabilecek geometrik özellikler ve malzeme seçimi uygun yapılmamış ise, çalışma esnasında makine elemanları üzerinde plastik deformasyon ve kırılma hasarları meydana gelebilmektedir. Bu tip istenmeyen hasarların önüne geçebilmek amacıyla makine ve alet tasarımlarında ileri düzey bilgisayar destekli tasarım ve mühendislik uygulamalarını kullanmak oldukça yararlı olmaktadır. Bu çalışmada 50 adet kapasiteli büyük baş hayvan yetiştiriciliğinin yapıldığı bir işletmeye uygun, $3.75 \mathrm{~m}$ sıyırma genişliğine sahip özel tasarım bir gübre sıyırıcı küreğinin üç boyutlu bilgisayar destekli tasarımı gerçekleştirilmiş ve gerçek çalışma koşulları altında uğradığı deformasyon davranışı sonlu elemanlar yöntemine göre analiz yürüten ticari bir yazılım ile analiz edilmiştir. Analizlerde hasar kriteri olarak malzeme akma dayanım değerleri referans alınmıştır. Gerçekleştirilen analiz neticesinde herhangi bir plastik deformasyon ya da kırılma hasarı izine rastlanılmamış ve en yüksek eşdeğer (Von Mises) gerilme değerine karşılık gelen malzeme güvenli çalışma katsayısı yaklaşı 1.368 olarak hesaplanmıştır. Analiz sonuçları ile tasarım geliştirme çalışmalarında kullanılabilecek faydalı görsel ve sayısal çıktılar ortaya konmuştur.

Anahtar Kelimeler: Gübre sıyırıcı, bilgisayar destekli mühendislik, sonlu elemanlar analizi, gerilme analizi

\section{Stress Analysis on Structural and Functional Elements of a Custom Design Manure Scraper by Means of Finite Elements Method}

\section{Abstract}

Manure scrapers are fundamental and efficient agricultural tools used in livestock production in order to reduce to labour. Two types of the scraper designs can be seen in the production areas: mechanical (chain trains) and hydraulic types. Most especially, mechanical types (chain trains) are commonly used types in the area; however, plastic deformation or fracture failures may be experienced on this type of tools during its operation because of the geometrical and material faults made in design or manufacturing processes or user faults. It is significantly useful to utilise computer aided design analysis applications in design of the agricultural machinery and tools in order to avoid undesired such failure cases. In this study, a custom design manure scraper, which has a working width of $3.75 \mathrm{~m}$, was designed 3-dimensionally and the deformation behaviour of the tool was analysed based on finite element method under pre-defined operating conditions. The material failure criterion was assigned as the yield stress point and safety factor of 1.368 (approximately) against maximum stress values was calculated in the simulation. The simulation results revealed useful visuals and numerical data regarding the tool's deformation behaviour and that it was not diagnosed any plastic deformation or fracture failures on the tool under defined working conditions.

Keywords: Manure scraper, computer aided engineering finite element analysis, stress analysis

\section{Giriş}

Hayvancılık işletmelerinde atık yönetimi, barınaklarda ortaya çıkan katı ve sıvı atıkların toplanmasını, uzaklaştırılmasını, biriktirilerek depolanmasını ve olgunlaştırıldıktan sonra tarlaya iletilerek çiftlik gübresi olarak kullanılmasını içeren geniş kapsamlı bir faaliyet olarak tarif 
edilmektedir (Olgun ve Polat, 2005). Yapılan çalışmalarda gelişen tarım ve hayvancılık doğrultusunda hayvan varlığına bağlı olarak ortaya çıkan gübre kontrolünün de gün geçtikçe zorlaştığı ve mekanizasyonun kaçınılmaz olduğu belirtilmektedir (Ergül, 1989; Jacobson ve ark., 1999; Şimşek ve ark., 2001; İnan, 2012).

$\mathrm{Bu}$ tip yetiştiricilik yapılan işletmelerde ahır içerisinde gübrenin uzun süre kalmaması ve günlük temizlik işlemleri dikkat edilmesi gereken önemli hususlardır. Bu noktada özellikle sağmal ineklerde sağımdan sonra meme gözlerinin enfeksiyonlara açık olmasından dolayı ineklerin kötü bakım koşullarında bulunması mastitis gibi sorunların da ortaya çıkmasına sebep olabilmektedir (Erkan Can ve Boğa, 2019). Hayvan barınaklarında üretilen gübre kontrol edilmez ve uygun koşullar altında değerlendirilmeden kontrolsüz şekilde dış ortama, yetiştiricilik yapılan çevreye terk edilirse çevre, insan ve diğer canlıların sağlığı için istenmeyen sonuçlar doğuracak, bitkisel üretimde fayda sağlanabilecek bir materyal olmasına rağmen zararlı bir atık haline gelecektir (Waskom, 1999). Bu konu Atılgan ve ark. (2006)'in Akdeniz Bölgesinde yaptıkları bir anket çalışmasıyla desteklenmektedir. $\mathrm{Bu}$ çalışmada belirtilen bölgede gübre yönetimi olmayan işletmelerde enfeksiyon ve barınak içi çevre koşullarının yetersizliğinden dolayı hayvan ölümlerinin arttı̆̆ ortaya konmuştur.

Hayvan barınaklarında gübre yönetim zincirinin ilk halkası olan gübre sıyırıcılar günümüzde hayvancılıkta mekanizasyonun vazgeçilmez ekipmanlarından birisidir. Genellikle bir bağ çekme mekanizması ile çalışan bu aletler çekilme tipine göre başlıca zincirli/halatlı (mekanik) ve pistonlu (hidrolik) olmak üzere iki grupta incelenebilmektedir. Zincirli/halatlı sıyırıcılarda, sistem başlıca iki sıyırıcı küreği, ilerleme hareketini veren bir sıyırıcı kulesi, elektrik motoru ve çekme işini gerçekleştiren zincirden oluşmaktadır. Kuledeki dönü hareketini veren makaradan geçen zincir, önce birinci sıyırıcı küreğine sonra ikinci sıyırıcı küreğine ardından tekrar kuleye, ahırın dört köşesindeki $90^{\circ}$ 'lik dönüşler veren makaralar ile sistemi tamamlamaktadır (Şekil 1). Küreklerden birincisi öne doğru sıyırma işlemini yaparken ikinci sıyırıcı, plakalarını kaldırarak geriye doğru gübreli alana bir müdahalede bulunmadan ahırın başına ulaşmaktadır. Gübre çukuruna, gübreyi boşaltan birinci kürek kurs sonuna gelip sınıra dayandığında, elektrik motorundaki zorlanmaya bağlı amperin yükselmesini anlayan devre kartı, sistemi tam tersi yöne çevirmektedir. Gübre sıyırıcının çalışma mekanizması bu şekilde git gel hareketlerine dayanmaktadır. Pistonlu sıyırıcılarda ise, gübre yolunun ortasında bir piston vasıtasıyla 30-40 cm aralıklarla ileri geri hareket yapan, üzeri özel deliklere sahip bir "U" profil kullanılmaktadır. Siyırıcı küreğindeki bir mekanizma ile bu git gel hareketi sayesinde küreklerin ileri ve geri gidiş dönüş hareketleri ile sıyırma işlemi gerçekleştirilmektedir.

Türkiye'de orta ve büyük ölçekli olarak nitelendirilen 50 baş sağmal ve üzerinde ineği olan işletme sayısı 26500 'ün üzerine çıkmıştır. Buna ek olarak yeni işletmeler de bir yandan banka kredileri veya öz kaynak kullanmak suretiyle hizla kurulmaktadır (Soyer, 2014). Örnek olarak 50 başlık bir süt sığırcılığı işletmesi göz önüne alındığında, günde yaklaşık 2500 kg gübrenin kontrolü söz konusu olmaktadır. Günümüzde bu tip işletmelerde yer alan mevcut gübre sıyırma ekipmanlarının yapısal olarak optimize edilmesi veya fonksiyonel elemanlarında tasarım iyileştirme çalışmalarının yapılması iş verimliliğini artırmak adına bir gereklilik olarak ortaya çıkmaktadır.

Alet-makine tasarımlarında, kullanım koşulları altında ortaya çıkabilecek olası mukavemet problemlerini ortadan kaldırmak amacıyla genellikle tasarım güvenlik katsayıları yüksek tutulmaktadır. Buna yönelik et kalınlığı yüksek veya ekonomik olmayan daha özel malzemeler kullanılmaktadır. Bu durum tasarlanan alet ve makinelerin güvenli koşullarda çalışmasını sağlamakla birlikte, kullanılan malzeme ağırlıklarının artmasına veya ekonomik olmayan malzeme kullanımından dolayı üretim maliyetlerinde artışa sebep olmaktadır (Çelik ve ark., 2007). Tasarımı tamamlanıp imal edilen alet - makinaların, sorunsuz bir şekilde çalışıyor olması her zaman optimum bir tasarım işleminin yapıldığı anlamına gelmeyebilir. Tasarım çalışmalarında temel amaç, çalışma şartlarını sorunsuz bir şekilde yerine getirebilecek, tanımlanan tasarım sınırları içerisinde optimum özelliklere sahip ekonomik tasarımın gerçekleştirilmesidir. Bu noktada en az ve uygun malzeme kullanımı ile en yüksek kullanım verimi elde etmek hedef fonksiyondur. (Çelik, 2006). Gelişmiş tasarım ve imalat alanlarında ve farklı mühendislik disiplinlerinde karmaşık tasarım problemlerini çözmek için sayısal yöntemler aktif bir şekilde kullanılmaktadır. Alet - makine tasarımlarında kullanılan sayısal yöntemlerden birisi olan "Sonlu Elemanlar Yöntemi” (FEM) temelli analiz tekniklerinin kullanımı gün geçtikçe yaygınlaşmaktadır. Günümüzde bu yöntem, gelişen tarım teknolojileri ve birçok makine 
tasarım aşamalarında, bilgisayarlarla birlikte farklı mühendislik alanlarında aktif olarak kullanılır durumdadır. Bu yöntemin, tarımsal mekanizasyon tasarım çalışmalarında da kullanımı gün geçtikçe artmaktadır (Çelik ve ark., 2008).

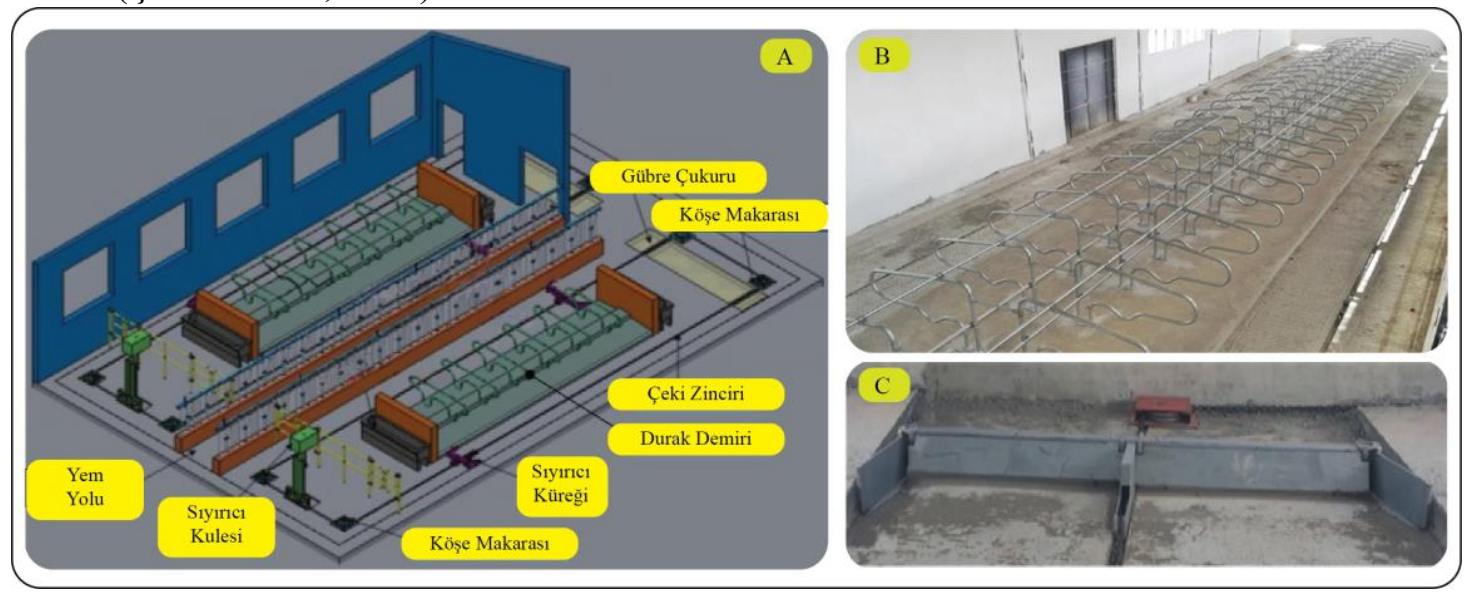

Şekil 1. (A) Ahır mekanizasyon planı (B) Gübre sıyırıcı yolu ve duraklar, (C) Gübre sıyırıcı küreği

$\mathrm{Bu}$ çalışmada, bir elektrik motoru ile hareket verilen özel tasarım bir sıyırıcı küreği üzerine odaklanılmış ve alet üç boyutlu parametrik bir katı modelleme yazılımı kullanılarak bilgisayar ortamında modellenmiştir. Takip eden aşamada aletin işletme çalışma koşullarındaki deformasyon davranışı ticari bir Sonlu Elemanlar Analizi (FEA) yazılımı kullanılarak simüle edilmiş ve alete ait elemanlar üzerindeki eşdeğer gerilme (Von-Mises) dağılımları haritalandırılmıştır.

\section{Materyal ve Yöntem}

Çalışmada ele alınan özel tasarım gübre sıyıcı küreğine ait tasarım ve modelleme detayları 50 başlık bir işletme büyüklügü dikkate alınarak hesaplanmıştır. Çalışma özelinde yaklaşık $500 \mathrm{~kg}$ canlı ağırlı̆̆a sahip bir süt sığırının günde yaklaşık $50 \mathrm{~kg}$ gübre ürettiği kabul edilmiştir (Baytekin 2013). 50 başlık bir işletmede bu değer $2500 \mathrm{~kg} g u ̈ n^{-1}$ olarak hesaplanmıştır. Bu büyükteki bir işletmede yer alan gübre sıyırma sisteminin günde iki kez çalıştırıldığı $(2500: 2=1250 \mathrm{~kg}$ ), toplamda ahırda iki sıyırıcı küreği olması durumunda her bir sıyırıcı kürek için her bir çalışmada maksimum 1 250:2=625 kg gübre kütlesi yükleyici kütle olarak hesaplanmıştır. Makinenin gübre yığınını bu yükleme kütlesi ile çektiği an kurgulanmıştır. FEA kurgusunda makineye ait gübre yayılım yüzeyleri sadece bası/sıkıştırmaya tepki veren özel mesnet ile tanımlanmış ve makine çeki demirinden çeki kuvveti $\left(625 \mathrm{~kg}\right.$ x $\left.9.81 \mathrm{~m} \mathrm{~s}^{1}{ }^{1} \approx 6135 \mathrm{~N}\right)$ ile yüklenmiştir. Optimum sıyırıcı yolu genişliği $3.75 \mathrm{~m}$ olarak belirlenmiştir. Çalışmada alet tasarımına ait üç boyutlu katı modelleme işlemleri SolidWorks parametrik katı modelleme yazılımı kullanılarak gerçekleştirilmiştir. Katı modelleme işlemlerinin ardından tasarlanan aletin işletmedeki tanımlanan çalışma koşulları altındaki deformasyon davranışı ANSYS Workbench sonlu elemanlar yöntemi kodu kullanılarak simüle edilmiştir. Simülasyon kurgusunda doğrusal statik yüklenme (maksimum yüke binme kuvveti: $6135 \mathrm{~N}$ ), homojen doğrusal izotropik malzeme modeli, hareketli bağlantı noktalarında sürtünmesiz temas (frictionless contact) ve kaynak yüzeylerinde doğrusal temas (bonded contact) kabulleri yapılmıştır. Kaynaklı parçaların ideal kaynak parametrelerine sahip olduğu ve kaynak işlemi sırasında herhangi bir 1sıl deformasyona uğramadığı kabul edilmiştir. Alet elemanları genel makine imalat alanlarında tercih edilen yapısal çelik esaslı malzemelerden imal edilmektedir. $\mathrm{Bu}$ nedenle alet elemanları için analiz kodu kütüphanesinden yapısal çelik malzeme tanımlaması yapılmıştır (Elastik Modül: $210 \mathrm{GPa}$, Akma Dayanımı: $250 \mathrm{MPa}$, Poisson Oranı: 0.3, Yoğunluk: 7,850 $\mathrm{kg} \mathrm{m}^{-3}$ ). Styırıcı küreğinin sonlu eleman modeli için ANSYS Workbench elemanlara ayırma fonksiyonları kullanılmıştır. Elemanlara ayırma işleminde model boyutları ve çözücü platform kapasitesi dikkate alınarak eleman boyutu belirlenmiştir ve sonlu eleman modelinde toplam 272604 adet düğüm noktası ve 68127 adet eleman elde edilmiştir. Yapının sonlu elemanlar modeli kalitesi Skewness eleman kalitesi kontrol parametresi kullanılarak kontrol edilmiştir. Skewness kalite kontrolü bir yapının sonlu elemanlar modelinin yapının geometrisini temsil etme derecesini değerlendirmek için kullanılan bir değerlendirme parametresidir. 
Çalışmada elde edilen elemanlara ayırma işlemi sonucunda ortalama Skewness kalite değeri 0.312 olarak elde edilmiş ve 0-1 (0: En iyi-1: Kabul edilemez) değerleri aralığında yapılan kriter değerlendirmesinde gerçek modeli iyi derece temsil edebilen bir sonlu eleman kalitesi elde edildiği anlaşılmıştır (ANSYS Doc., 2019). Çalışmada ele alınan alete ait katı model ve FEA kurgusu detayları Şekil 2'de verilmiştir.

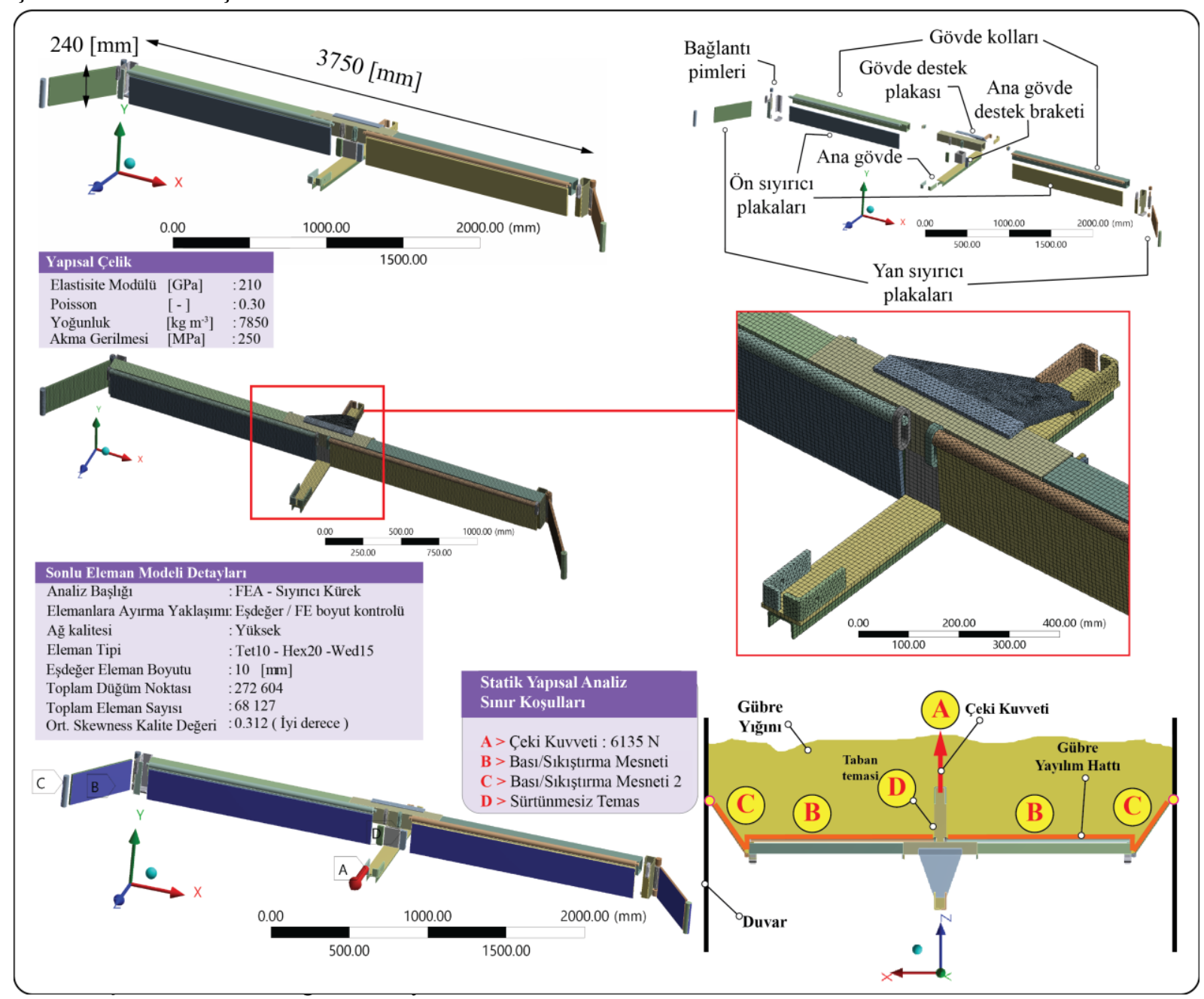




\section{Bulgular ve Tartışma}

İşlem öncesi adımların tamamlanmasının ardından hazırlanan model statik analiz kurgusu ile çözdürülmüştür. Gerçekleştirilen FEA sonucunda gübre sıyırıcı küreğinin tanımlanan yük altında uğradığı deformasyon davranışı başarı ile simule edilebilmiş ve alet elamanları üzerinde meydana gelen eşdeğer gerilme (Von Misses) dağılımları ve yer değiştirmelere ait sayısal değerler elde edilmiştir. FEA çıktıları alet üzerinde meydana gelen en yüksek eşdeğer gerilme değerinin 182.79 $\mathrm{MPa}$, tüm yapı için hesaplanan en yüksek yer değiştirme değerinin $2.02 \mathrm{~mm}$ olduğunu göstermiştir. Alet elemanlarının tanımlanan yük altında uğradığı deformasyon davranışını ve eşdeğer gerilme dağılımlarını gösteren simülasyon çıktıları Şekil 3'de verilmiştir. Gerçekleştirilen analizde hasar kriteri elemanların plastik deformasyona geçiş noktası olan malzeme akma dayanımı değeri (Akma Dayanımı: $250 \mathrm{MPa}$ ) kabul edilmiştir. FEA eşdeğer gerilme sonuçları alet için tanımlanan malzeme akma dayanımı referans alınarak tüm alet elemanları için değerlendirilmiştir. Başlıca elemanlar bazında yapılan değerlendirmede, gübre sıyırıcı küreği elemanlarının güvenli çalışma katsayıları (GÇK) hesaplanmıştır (Çizelge 1). Değerlendirme sonucunda en düşük GÇK değeri maksimum gerilme değerinin hesaplandığ 1 ana gövde destek braketi üzerinde 1.368 olarak hesaplanmıştır.

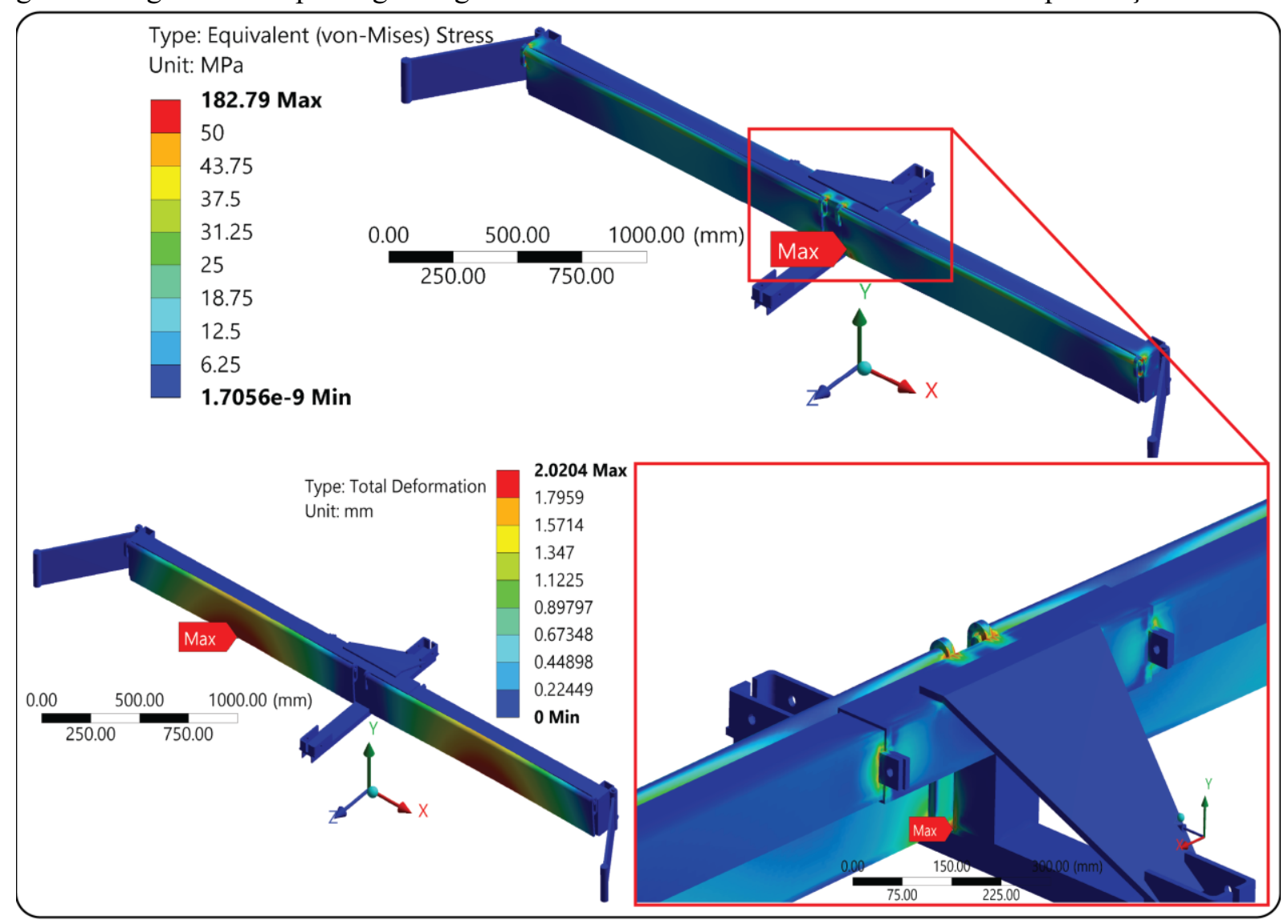

Şekil 3. FEA çıktıları ve başlıca elemanlar üzerinde hesaplanan eşdeğer gerilme ve deformasyon dağılımları 


\begin{tabular}{|c|c|c|c|}
\hline Alet Bileșeni & $\begin{array}{c}\text { Malzeme Akma } \\
\text { Dayanımı } \\
{[\mathrm{MPa}]} \\
\left(\sigma_{\text {Akma }}\right)\end{array}$ & $\begin{array}{l}\text { Maks. Ess. Gerilme } \\
\text { Değeri (FEA) } \\
\text { [MPa] } \\
\left(\sigma_{\text {Esdeğer }}\right)\end{array}$ & $\begin{array}{c}\text { Güvenli Çalışma Katsayısı } \\
{[\text { - }]} \\
\left(\text { GÇK }=\sigma_{\text {Akma }} \sigma_{\mathrm{Eşdeğer}}\right)\end{array}$ \\
\hline Ana Gövde Destek Braketi* & & 182.790 & 1.368 \\
\hline Ön Sıyırıcı Plakaları & & 105.200 & 2.376 \\
\hline Gövde Kol Profilleri & 250 & 100.630 & 2.484 \\
\hline Ana Gövde (Çeki Bağlantısı ile) & & 58.172 & 4.298 \\
\hline Gövde Destek Plakası & & 14.549 & 17.183 \\
\hline Yan Siyırıcı Plakaları & & 10.473 & 23.871 \\
\hline
\end{tabular}

* Maks. Eşdeğer Gerilme Noktası

Gerçekleştirilen FEA neticesinde ortaya çıkan en yüksek deformasyon değerinin; ( $2.02 \mathrm{~mm}$ ) aletin çalışmasında herhangi bir istenmeyen işlem bozukluğuna sebep olamayacak bir değer olduğuna kanaat getirilmiştir. Alet üzerinde ortaya çıkan eşdeğer gerilmeler ise alet üzerinde hiçbir noktada hasar kriteri olan malzeme akma dayanım değerini ( $250 \mathrm{MPa}$ ) aşmamıştır. Nihai değerlendirme ile alete ait elemanların tanımlanan yük altında herhangi bir plastik deformasyon hasarı olmadan çalışabildiği söylenebilmektedir. Bununla birlikte aleti oluşturan başlıca elemanların GÇK değerleri (Çizelge 1) değerlendirildiğinde, ana gövde destek braketinin genel güvenlik kabulü olan geleneksel tasarım analizlerinde kabul edilen GÇK (1.5-2 kat) değerinden bir miktar düşük kaldığı, bununla birlikte, bazı elemanlarda GÇK değerlerinin statik ve dinamik yüklemelerde hesaplanan GÇK değerlerinin (2-5 kat) çok üzerinde olduğu görülmektedir. Bu durum GÇK yüksek bu elemanların güvenli çalıştığını göstermekle birlikte alet üzerinde gereğinden fazla ağırlık yükü oluşturduğunu işaret etmektedir. Bu nedenle yüksek GÇK değerleri taşıyan bu elemanlar için ağırlık azaltma hedefi ile bir yapısal optimizasyon çalışması yapılmasının uygun olacağı söylenebilmektedir. Gerçekleştirilecek yapısal optimizasyon çalışması ile alet tanımlanan mukavemet değeri ile daha hafif bir ağırlığa sahip olabilecek, alet operasyonlarında kullanılan hareket kaynakları (elektrik motoru) daha az zorlanacak, malzeme tasarrufu yapılabilecek ve dolayısıyla imalat bütçesi azaltılabilecektir.

\section{Sonuç ve Öneriler}

$\mathrm{Bu}$ çalışma kapsamında günümüzde 50 baş ve üzeri büyükbaş hayvan yetiştiriciliği yapılan ahırlarda ihtiyaç duyulan, hayvancılıkta gübre yönetiminde kullanılan en temel ekipmanlarından biri olan özel tasarım bir gübre sıyırıcı küreği tasarımında ileri düzey bilgisayar destekli tasarım ve mühendislik uygulamalarının örneklendirilmesi üzerine odaklanılmıştır. Çalışmada ileri düzey bilgisayar destekli mühendislik uygulamaları ile montaj işçiliği kolay, imalat işçiliği ve imalat zamanından tasarruf edilebilecek, nakliye ve taşıma işlemlerinin daha kolay yapılabildiği özel tasarım bir ürüne ait mukavemete dayalı bir tasarım analiz örneği sunulmuş ve hayvan işletmelerinin iş verimliliğine ve makine imalatçılarının ticari karlılı̆̆ına fayda getirecek bir ürün tarifi başarı ile yapılabilmiştir. $\mathrm{Bu}$ doğrultuda gerçekleştirilen çalışma ile bu araştırma özelinde hedeflenen amaçlara başarı ile ulaşılmıştır. Buna ek olarak çalışma özelinde bazı önemli teknik noktalar aşağıdaki şekilde stralanabilir.

- $\quad$ FEA sonucunda modelin tüm yapısında en yüksek eşdeğer (Von Mises) gerilme değeri sıyırıcı kapak destek braketinde $182.79 \mathrm{MPa}$ olarak hesaplanmıştır. Bu değer tanımlanan plastik deformasyon hasar kriteri değerinin (Malzeme akma gerilmesi: $250 \mathrm{MPa}$ ) altındadir.

- Gübre sıyırıcı küreği üzerinde maksimum yer değiştirme değeri $2.02 \mathrm{~mm}$ olarak hesaplanmıştır. $\mathrm{Bu}$ değer tasarımın çalışma koşullarında tanımlanan fonksiyonları bir engel olmadan yerine getirmesi için öngörülen tasarım sınırları içerisinde yer almaktadır. 
- Yapılan simülasyon sonucunda gübre sıyırıcı küreğine ait hiçbir eleman üzerinde herhangi bir plastik deformasyon veya kırılma hasarı izine rastlanmamıştır.

- $\quad$ En yüksek eşdeğer (Von Mises) gerilme değerine karşılık gelen malzeme güvenli çalışma katsayısı yaklaşık 1.368 olarak hesaplanmıştır. Bununla birlikte aleti oluşturan başlıca elemanların GÇK değerleri 2 katın üzerinde bulunmuştur.

- Aleti oluşturan başlıca elemanlarda elde edilen göreceli olarak yüksek GÇK değerleri bu elemanlar üzerinde ağırlık azaltma hedefi ile yapısal optimizasyon çalışmalarının yapılabilirliğini işaret etmektedir.

Not: Bu çalışma 32. Ulusal Tarımsal Mekanizasyon ve Enerji Kongresinde (04-06 Eylül 2019 - Çanakkale) poster sunumu yapılan ve kongre bildiri özetleri kitabında (ISBN:978-605-4222-78-0) yer alan özet çalışmanın genişletilmiş orijinal tam metinidir.

\section{Kaynaklar}

ANSYS Software Product, 2019. Release 19.0 Documentation for ANSYS Workbench.

Atılgan, A., Erkan, M., Saltuk, B., Alagöz, T., 2006. Akdeniz bölgesindeki hayvancılık işletmelerinde gübrenin yarattığı çevre kirliliği. Çevre Koruma ve Araştırma Vakfı dergisi, Ekoloji. 15(58): 1-7.

Baytekin, H., 2013. Bitkisel Üretimde Çiftlik Gübresi ve Biyogaz Kompostu Kullanımının Yaygınlaştırılması. Türk - Alman Biyogaz Projesi. 34 s. Ankara.

Çelik, H.K., 2006. Dişli pompalarda dişli çark ve gövdenin sonlu elemanlar yöntemi ile gerilme analizi. Kocaeli Üniversitesi, Fen Bilimleri Enstitüsü, Makine Eğitimi Anabilim Dalı, Yüksek Lisans Tezi. 72 s.

Çelik, H.K., Topakcı, M., Yılmaz, D., Akıncı, İ., 2007. Çizelin yapısal ve işlevsel elemanlarında sonlu elemanlar yöntemi ile mukavemet analizi. Tarım Makinaları Bilimi Dergisi. 3: 111-116.

Çelik, H.K., Yılmaz, D., Akıncı, İ., 2008. Structural stress analysis under the static load of a tractor mounted lifting apparatus. International Conference of Agricultural Engineering XXXVII Brazilian Agricultural Engineering International livestock Symposium-ILES VIII, Iguassu Falls City, , vol.1, 4-4. 31 Ağustos 4 Eylül Brezilya.

Ergül, M., 1989. Hayvansal üretim ve çevre kirliliği. Yem Sanayi Dergisi. 64: 20-25..

Erkan Can, M., Boğa, M., 2019. Niğde ili sığırcılık işletmelerinde atık yönetimi. KSÜ Tarım ve Doğa Dergisi. 22(2): 260-269.

İnan, F.İ., 2012. Hayvansal atıkların ve arıtma çamurlarının stabilizasyonunda kullanılan kompostlama ve anaerobik çürütme proseslerinin verimliliklerinin karşılaştırılması. Uludağ Üniversitesi, Fen Bilimleri Enstitüsü, Çevre Mühendisliği Anabilim Dalı, Yüksek Lisans Tezi. 1 s.

Jacobson, L.D., Moon, R., Bicudo, J., Yanni, K., Noll, S., 1999. Generic environmental impact statement on animal agriculture. A Summary of the Literature Related to Air Quality and Odor (H). Animal Science, University of Minnesota: H-7 s. Minnesota.

Soyer, G., 2014. Aydın ili süt sığırcılığı işletmelerinde gübre yönetim uygulamaları ve bitkisel üretimde gübre kullanım olanaklarının geliştirilmesi. Adnan Menderes Üniversitesi, Fen Bilimleri Enstitüsü, Tarımsal Yapılar ve Sulama Anabilim Dalı, Yüksek Lisans Tezi. 3 s.

Şimşek, E., Yaslıoğlu, E., Arıcı, İ., 2001. Süt sığırcılığı işletmelerinde gübre yönetimi ve gübre işletim sistemlerinin planlanması. GAP II. Tarım Kongresi. 2, 715-722. 24-26 Ekim, Şanlıurfa.

Olgun, M., Polat, H.E., 2005. Ülkemizdeki hayvancılık işletmelerinde atık yönetim sistemlerinin değerlendirilmesi. 6. Ulusal Çevre Mühendisliği Kongresi. Poster Bildiriler Kitabı, 211 s. 24-25-26 Kasım, İstanbul.

Waskom, R.M., 1999. Best management practices for manure utilization. 568A, Colorado State University Cooperative Extension, Fort Collins, no. 568A. Colorado. 